\title{
Growth of melon cultivated in coconut fiber under different concentrations of nutrient solution
}

\author{
Christiano Rebouças Cosme, Nildo da Silva Dias*, Karen Mariany Pereira Silva, \\ John Lenon Vasconcelos Fonteles, Marcelo Tavares Gurgel, Cleyton dos Santos Fernandes
}

Federal Rural University of the Semi-Arid, Mossoró, Brazil

*Corresponding author, e-mail: nildo@ufersa.edu.br

\begin{abstract}
To evaluate the effects of applying different concentrations of the nutrient solution macronutrients in growth of melon cultivated in coconut fiber it was conducted this experiment uses the 'Galia' melon (Cucumis melo L., hybrid Babilonia RZ F1). The experimental design was a randomized blocks utilizing five treatments, which corresponded to different concentrations of macronutrients in nutritive solutions (corresponding to different levels of nutrient solution macronutrients) based on the standard solution for the melon proposed by Furlani: 100 (control), 75, 50, 25, and 12.5\%, applied in five replications. The concentration of $50 \%$ provided higher production of dry matter of the aerial part and leaf area. The absolute aerial part growth rate showed different tendencies for levels being that concentration of $50 \%$ produced the best results. The relative growth rate of the aerial part and assimilation rate of the aerial part decrease with time for all concentrations of the nutrient solutions tested.
\end{abstract}

Keywords: Cucumis melo L., soilless cultivation, substrate

\section{Introduction}

The melon (Cucumis melo L.) is a fruit which is widely produced in Brazil, and occupies a prominent position regarding exports, being a culture of great importance for the states of the Northeast Region. Among these, the state of Rio Grande do Norte appears as the largest producer in Brazil, both for the strategic geographic position as well as by the edaphoclimatic conditions that favor genotype $x$ environment interaction (Kill et al., 2011).

Recently, cultivars of noble melons, such as Gaul and Cantaloupe, which have a high commercial value have increased its market share by 15 to 20\%, although production and commercialization require more technologies, management with fertilization and post-harvest management than the common melons, reasons for having the highest cost of production (Mascarenhas et al., 2010).

In the last decades, there has been an increase in the production of melons in protected cultivation, and this fact is due to the possibility of greater profitability that can be achieved in small areas, during some periods of the year, bringing the alternative of adapting the environment to the plant and increase the productive period of these species (Castoldi et al., 2008).

However, the growing demand for quality melons combined with problems such 
as scarcity of arable land, salinization of soil, occurrence of weeds and pathogens make it challenging to manage crops, awaken the search for alternatives that ensure increasingly technified and competitive production, that serves the consumer market (Silva et al., 2012). In this perspective, the crops without soil, which consists of cultivating the plants with roots entirely or partially immersed in a nutrient solution, appear as reliable alternatives.

Hydroponic cultivation systems present very generalized information on formulations of nutrient solutions for different crops, influencing their yield, since the tolerance of plants to the salinity of the nutrient solution in hydroponic systems is higher than the conventional method, and the absorption of the nutrients is proportional to their concentration in the solution near the roots (Dias et al., 2010).

One of the current challenges of vegetable production is the generation of nutritional information due to the enormous diversity of species, genetic material and existing production systems (Furlani, 1999). According to the author, the success of the production of vegetables depends on information about the methods of production, management, and, mainly, nutrition. Thus, there is a need for more specific studies on fertilization for each species associated with the production system, as well as local climatic conditions.

Therefore, the objective of this research was to evaluate the effects of different concentrations of macronutrients in the nutrient solution on the growth of the melon in a hydroponic system with coconut fiber, based on the standard solution for the melon proposed by Furlani.

\section{Materials and Methods}

The experiment was carried out from February to May 2015 in a protected environment, in the Department of Environmental and Technological Sciences of the Federal Rural University of the Semi-Arid - UFERSA, in MossoróRN (latitude $5^{\circ} 11^{\prime}$ south and longitude $37^{\circ} 20^{\prime}$ west and an average altitude of $18 \mathrm{~m}$ above sea level).

The protected environment consists of a $6.4 \mathrm{~m}$ wide, $18 \mathrm{~m}$ long and $3.0 \mathrm{~m}$ high covered with low-density polyethylene film with antiultraviolet additive and a thickness of $150 \mu \mathrm{m}$, protected on the sides with black mesh $50 \%$.

The experimental design was a randomized block, with five treatments and five replicates, totaling 25 experimental units. The treatments consisted of five concentrations of macronutrients ( $\mathrm{N}, \mathrm{P}, \mathrm{K}, \mathrm{Ca}, \mathrm{Mg}$ and $\mathrm{S}$ ) in the nutrient solution, based on the standard solution for the melon proposed by Furlani (1999) $\left(\mathrm{T}_{1}=\right.$ $100 \%$ ) and dilutions of $\mathrm{T}_{2}=75 ; \mathrm{T}_{3}=50, \mathrm{~T}_{4}=25$ and $\mathrm{T}_{5}$ $=12.5 \%($ Table 1$)$.

For the production of the nutrient solution (Table 2), the water used came from the municipal supply system. The nutrient solutions were dissolved in $300 \mathrm{~L}$ of water for the treatment composition. During the preparation of the solution, each fertilizer was diluted individually in a smaller reservoir and then added to the main reservoir.

The concentrated solution containing the micronutrients was prepared previously and diluted in $1 \mathrm{~L}$ of distilled water and added to the main tank with the aid of a graduated beaker. The $\mathrm{pH}$ of the nutrient solution was adjusted to remain in the range of 5.5 to 6.6. The electrical conductivity of the solution (ECS) was monitored weekly with a conductivity meter in the reservoir

Table 1. Composition of the nutrient solutions of the treatments used in the experiment.

\begin{tabular}{|c|c|c|c|c|c|c|c|c|c|c|c|c|}
\hline \multirow{2}{*}{ Treatment } & $\mathrm{N}$ & K & $P$ & $\mathrm{Ca}$ & $\mathrm{Mg}$ & $S$ & $B$ & $\mathrm{Cu}$ & $\mathrm{Mn}$ & Mo & $\mathrm{Zn}$ & $\mathrm{Fe}$ \\
\hline & \multicolumn{12}{|c|}{$\mathrm{mg} \mathrm{L}^{-1}$} \\
\hline$T_{1}-100 \%$ & 210.5 & 270.0 & 50.0 & 170.0 & 40.0 & 52.0 & 0.5 & 0.1 & 0.5 & 0.05 & 0.3 & 2.2 \\
\hline $\mathrm{T}_{2}-75 \%$ & 157.9 & 202.5 & 37.5 & 127.5 & 30.0 & 39.0 & 0.5 & 0.1 & 0.5 & 0.05 & 0.3 & 2.2 \\
\hline $\mathrm{T}_{3}-50 \%$ & 105.3 & 135.0 & 25.0 & 85.0 & 20.0 & 26.0 & 0.5 & 0.1 & 0.5 & 0.05 & 0.3 & 2.2 \\
\hline $\mathrm{T}_{4}-25 \%$ & 52.6 & 67.5 & 12.5 & 42.5 & 10.0 & 13.0 & 0.5 & 0.1 & 0.5 & 0.05 & 0.3 & 2.2 \\
\hline $\mathrm{T}_{5}-12.5 \%$ & 26.3 & 33.8 & 6.3 & 21.3 & 5.0 & 6.5 & 0.5 & 0.1 & 0.5 & 0.05 & 0.3 & 2.2 \\
\hline
\end{tabular}


Table 2. Amounts of fertilizers and reagents used to prepare the nutrient solutions.

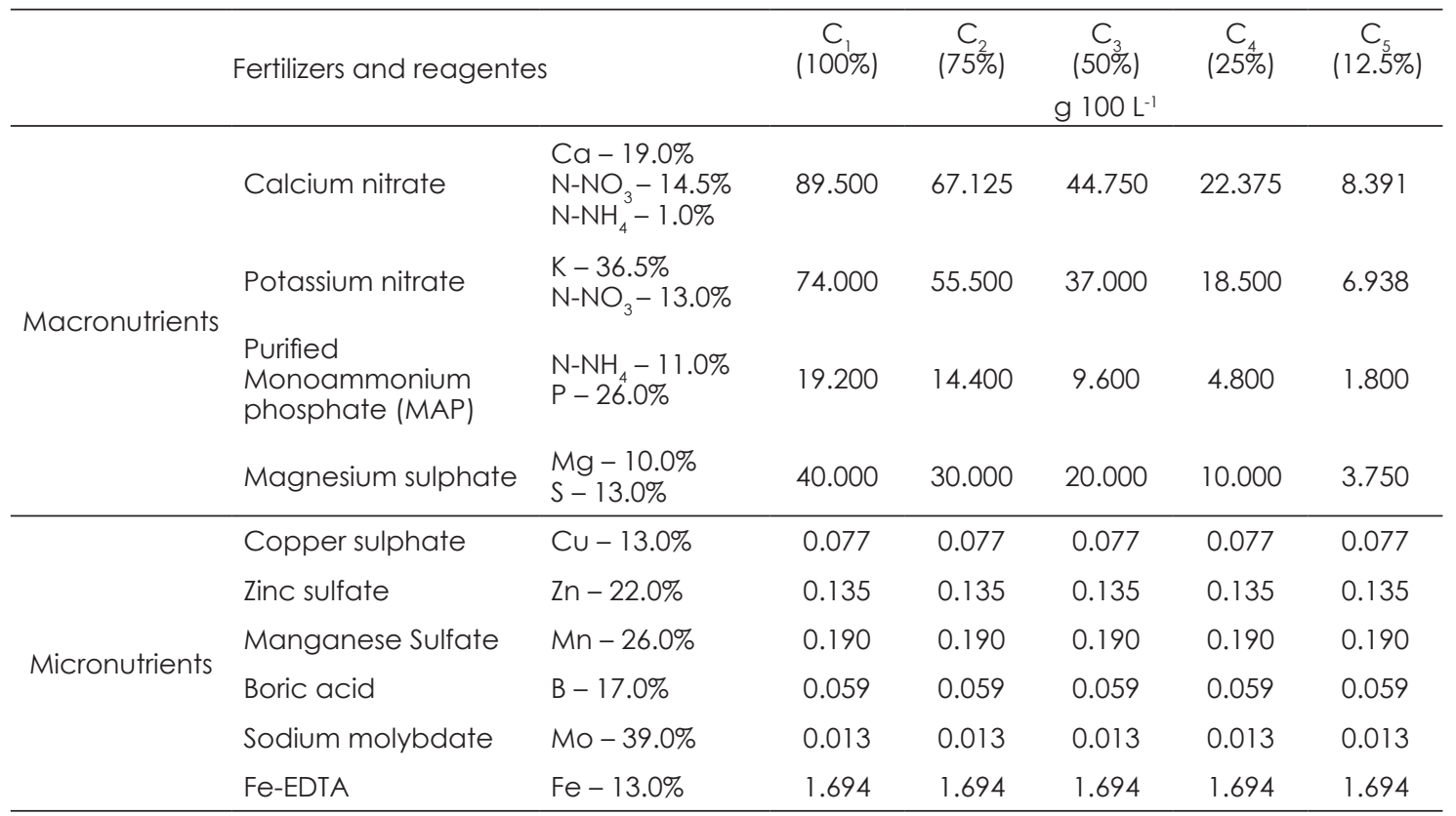

of each treatment, for the replacement of the nutrients. The average EC of each treatment after the production of the nutrient solutions was: $C_{1}=2.4 ; C_{2}=1.9 ; C_{3}=1.4 ; C_{4}=0.9$ and $C_{5}=0.7$ dS $\mathrm{m}^{-1}$

For storage of the nutrient solution, five tanks with a capacity of $300 \mathrm{~L}$ each were used, remaining capped to avoid heating, algae development, and evaporation of nutrient solutions.

The applications of the nutrient solutions were performed through the automated irrigation system using microtubes $(\varnothing=1 \mathrm{~mm})$ as an emitter, one emitter per plant. Six daily irrigations were performed, spaced two hours apart, to keep the pots in their maximum water storage capacity. Saturation was confirmed at the time of solution drainage. The drained solution was recycled through leachate collection and recirculation. Figure 1 shows the volume of nutrient solution applied during the growing period of the melon.

The 'Galia' melon seedlings (Babylon RZ - RijkZwaan ${ }^{\circledR}$ hybrid) were produced in 128 - cell polystyrene trays containing coconut fiber substrate. The seedlings were manually irrigated with low salinity water from the water supply system, without the addition of fertilizers. At 15 days after germination, the seedlings were transplanted to the definitive site.

After transplanting, the plants were

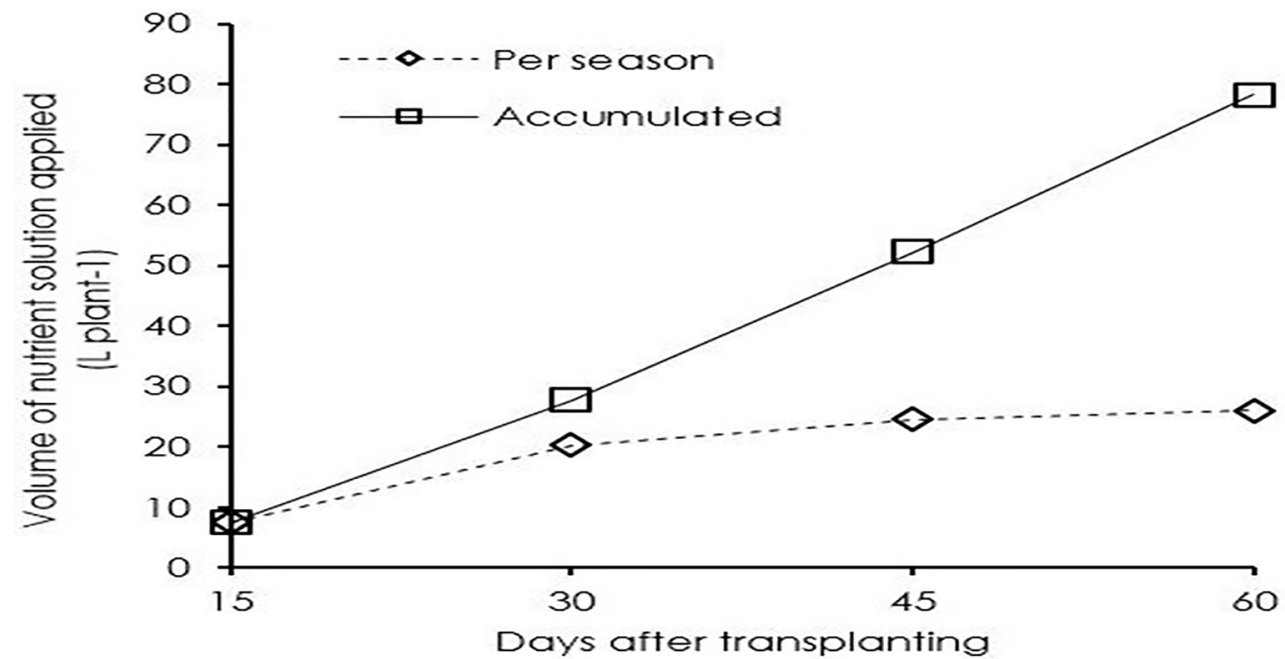

Figure 1. Volume of nutrient solution applied during the period of melon cultivation. 
conducted on a single stem in vertical espaliers.

Pruning was carried out weekly to eliminate lateral shoots, leaving only the sprouts destined to fruit development. Then these were pruned from the first leaf after the fruit.

The pollination was manual, it occurred at 35 days after the transplant, in the first hours of the morning. After the flourish of the fruits, the thinning leaved two fruits per plant.

Measurements for growth analysis were performed on all plants every fortnight, and then one plant per plot was collected for the destructive evaluations.

The growth variables evaluated were: Plant height (PHt), measure of the surface of the cultivation channel to the apical bud of the plant, with the aid of a scale graded in millimeters; Number of leaves (NL), obtained by counting healthy leaves; Stem dry matter (SDM); Leaf dry matter (LDM), obtained by weighing the respective materials after drying at $65^{\circ} \mathrm{C}$ in a greenhouse until constant weight; Dry matter of the aerial part (DMAP), obtained by the sum of the SDM and the LDM and; Leaf area (LA), calculated by adding the leaf areas of all leaves greater than $3 \mathrm{~cm}$, obtained through images using CAD software.

In addition, the physiological variables were evaluated: Specific leaf area (SLA), calculated by correlating the best fit curve of the LA with the best fit curve of the dry matter mass of the leaf itself (DMMLI); Leaf area ratio (LAR), obtained by the relation between the best fit curve of the LA and the best fit curve of the DMS; Leaf area index (LAI), calculated by the leaf area ratio and spacing (S) between plants (vases); Absolute aerial part growth rate (AAPGR) was determined by deriving the adjusted equation for LMS in relation to time ( $g$ day $^{-1}$ ); Relative aerial part growth rate (RAPGR) was estimated through the relationship between the ESCF equation and the best-fit equation providing the instantaneous DMS value $\left(\mathrm{g} \mathrm{g}^{-1} \mathrm{day}^{-1}\right)$ and the net assimilation rate of aerial part (NARAP), was obtained by the relation between the equation of ESCF and the best fit equation that gives the instantaneous value of LA ( $\left.\mathrm{g} \mathrm{m}^{-2} \mathrm{day}^{-1}\right)$.

The growth and physiological variables of the plants were analyzed, considering the concentrations repeated in the time (DAT), establishing relations between the characteristics and the age of the plant through the analysis of polynomial regression. Regardless of the significance of the interactions, the analysis of the deployment for the factors.

\section{Results and Discussion}

The analysis of variance for the parameters of the growth analysis of the melon showed that the concentrations of the nutrient solution caused significant effects for all the analyzed parameters, except for the number of leaves (NL). Analyzing the time factor, represented by the days after transplanting (DAT), the effect was significant $(P<0.01)$ for all the variables studied.

In the interaction of concentrations x DAT, there was no significant effect on the number of leaves ( $\mathrm{NL}$ ), plant height (PHt) and stem dry matter (SDM), while for the other variables, the interaction was significant. However, regardless of the significance of the interaction, it was performed the analysis of the DAT splitting for each concentration of the nutrient solution for all evaluated variables.

The plant heights presented a cubic fit for all the concentrations due to collection times, except for the $C_{5}$ concentration, which showed a quadratic adjustment. The concentrations $C_{1}$ and $C_{2}$ were significant at $5 \%(p<0.05)$, while the others were significant at $1 \%(p<0.01)$ of probability (Figure 2).

It was observed a more significant growth of the plants until the 30 DAT; there was a reduction in the growth after this period. The highest plant height (PHt) was $58.83 \mathrm{~cm}$ between the 15 and 30 DAT for the $T_{3}$, followed by the $T_{4}$ and $T_{2}$ treatments $(57.35$ and $56.91 \mathrm{~cm}$ plant $^{-1}$, respectively). At 45 DAT, all treatments reached more than $80 \%$ of final height. Yamaki (2005) obtained different model responses for the height of melon plants as a function of the concentration of the nutrient solution. However, the values observed in this study agree with those presented by this author.

The number of leaves (NL) of the melon as a function of days after transplanting (DAT) revealed by the cubic response regression 
analysis for treatments $T_{1}, T_{3}$, and $T_{4}$. The response for the treatments $\mathrm{S}_{2}$ and $T_{5}$ was quadratic (Figure 3). Number of leaves increased steadily to approximately 45 DAT tending to decrease growth to the end of the cycle for $T_{1}, T_{3}$, and $T_{4}$. The $\mathrm{T} 4$ reached the maximum number of leaves at 54 DAT, 38.36 leaves. The treatments $T_{2}$ and $T_{5}$ continued to increase until the end of the cycle when they reached the maximum number of leaves: 36.87 and 38.85, respectively. Queiroga et al. (2007) obtained a quadratic response on the number of leaves with $\mathrm{N}$ doses equal to 337.4 $\mathrm{kg} \mathrm{ha}{ }^{-1}$. The authors estimated a maximum of 46.6 leaves of the Cantalupensis melon under protected environment, raising NL by $23.5 \%$.

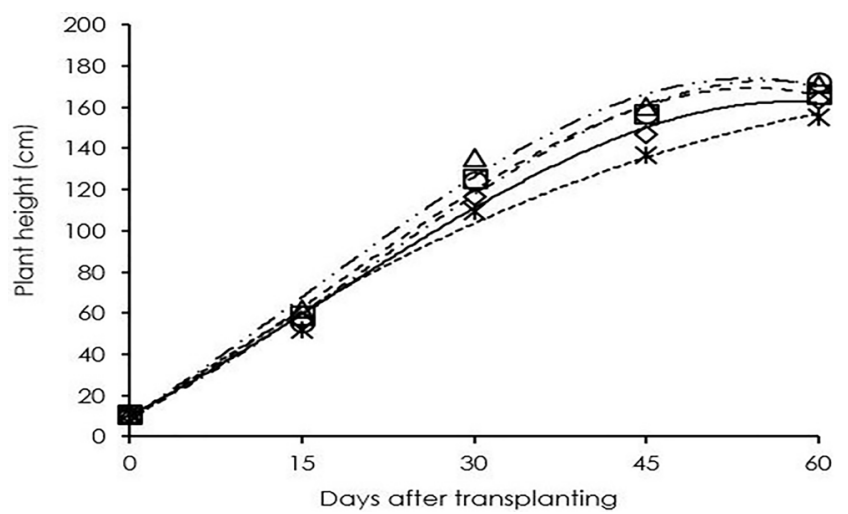

$$
\begin{aligned}
& \$ 100 \quad \square 75 \quad \Delta 50 \quad 025 \quad * 12.5 \\
& \begin{array}{c}
y(100)=-0.0007 \times 3^{*}+0.0377 \times 2+2.8764 x+10.351 \\
R^{2}=0.99^{*}
\end{array} \\
& \begin{array}{c}
y(75)=-0.001 \times 3^{*}+0.0549 \times 2+2.9029 x+10.261 \\
R^{2}=0.99^{*}
\end{array} \\
& y(50)=-0.0009 \times 3^{* * *}+0,042 \times 2+3,4501 x+9,6962 \\
& y=-0.001 x^{3}+0.0629 x^{2}+2.6144 x+10.058 \\
& \begin{array}{c}
y(12.5)=-0,0236 \times 2^{* *}+3,9062 x+7,6893 \\
R^{2}=0.99^{* *}
\end{array}
\end{aligned}
$$

Figure 2. Plant height (PHt) of the melon submitted to different concentrations of the nutrient solution throughout the cycle. *Significant at $5 \%(p<0.05)$; **Significant at $1 \%(p<0.01)$.

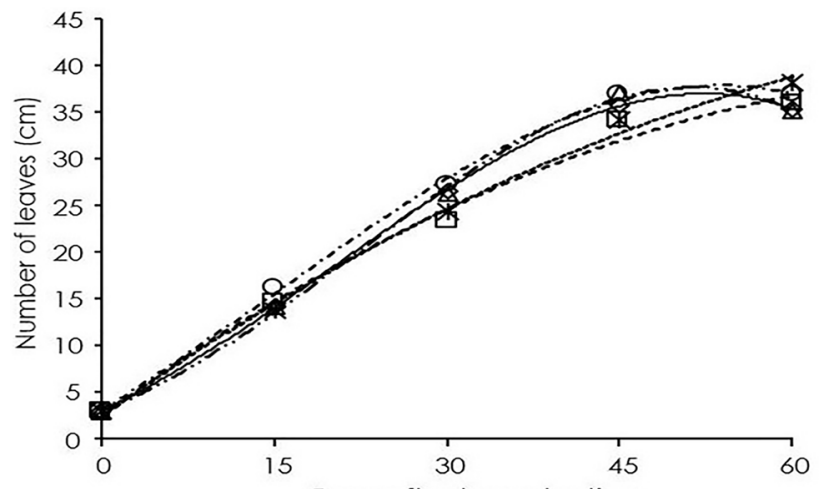

$$
\begin{aligned}
& \diamond 100 \quad \square 75 \quad \Delta 50 \quad 025 \quad * 12.5 \\
& \begin{array}{r}
y(100)=-0.0003 x^{3 * *}+0.0155 x^{2}+0.5686 x+3.0157 \\
R^{2}=j^{* *}
\end{array} \\
& \begin{array}{c}
y(75)=-0.0056 x^{2 * *}+0.9072 x+2.5986 \\
R^{2}=0.99^{* *}
\end{array} \\
& y(50)=-0.0003 x^{3 * *}+0.0218 x^{2}+0.4567 x+3.12 \\
& y(25)=-0.0002 x^{3 * *}+0.0074 x^{2+} 0.7747 x+3.1319 \\
& \mathrm{R}^{2}=0.99^{* *} \\
& y(12.5)=-0.0046 x^{2 * *}+0.8818 x+2.5 \\
& \mathrm{R}^{2}=0.99^{* *}
\end{aligned}
$$

Figure 3. Number of leaves (NL) of the melon submitted to different concentrations of the nutrient solution throughout the cycle. **Significant at $1 \%(p<0.01)$.

No significant adjustments were made to any mathematical model for the number of leaves (NL) of the melon for the sampling moments as a function of the concentration of the nutrient solution. This behavior indicates that this variable was not sensitive to the concentrations of nutrients applied in each treatment. It is worth noting that in the present experiment the secondary branches were sown which positively influenced the proximity of the mean values of the treatments in all the sampling dates. Gratieri et al. (2013) observed an increase in the number of leaves of the melon (Bonus hybrid No. 2) cultivated in coconut fiber at 20 DAT when nitrogen and potassium concentrations in the nutrient solution were increased. According to the authors, a maximum of 7.2 leaves plant $^{-1}$ occurred with the highest levels of $N$ and $K(280$ and $312 \mathrm{mg} \mathrm{L}^{-1}$, respectively).

For leaf dry matter (LDM), the predominant adjustment was linear ( $P<0.01$ ) for treatments $T_{1}, T_{2}$, and $T_{5}$, whereas treatments $T_{3}$ and $T_{4}$ fit the cubic model (Figure 4A). Leaf dry matter reached maximum values at 60 DAT for all treatments. Treatment $\mathrm{T}_{3}$ had the highest production of SPS, reaching $45.27 \mathrm{~g}$ plant $^{-1}$, followed by $T_{2}, T_{1}$ and $T_{4}$ treatments $(40.94,39.41$ and $36.66 \mathrm{~g} \mathrm{plant}^{-1}$, respectively). The $\mathrm{T}_{5}$ treatment obtained only $28.26 \mathrm{~g} \mathrm{plant}^{-1}$. Santos et al. (2015), cultivating the cantaloupe melon in soil under agro-textile protection, observed linear, quadratic and exponential behaviors of leaf dry matter as a function of days after transplanting. 
presented on average the highest percentage with $80.07 \%$.

The development of leaf area (LA) as a function of DAT is shown in Figure 6. The treatments $T_{1}, T_{2}$ and $T_{5}$, fit the quadratic model, while $T_{3}$ and $T_{4^{\prime}}$ to the cubic model.

Leaf area increase was higher at the beginning of the cycle until 30 DAT, when, on average, the treatments reached $71.74 \%$ of the total leaf area. In the interval between 0 and 15 DAT, the highest increases in FA for all treatments occurred, the highest for $\mathrm{T}_{1}$ and the lowest for $\mathrm{T}_{5}$ ( 1820.20 and $1276.63 \mathrm{~cm}^{2}$ plant ${ }^{-1}$ ). The $\mathrm{T}_{3}$ treatment obtained the highest value of leaf area, with its maximum registering $4857.29 \mathrm{~cm}^{2}$ plant $^{-1}$ at 54 DAT. Queiroga et al. (2007), verified the relation between $\mathrm{N}$ and leaf area. The author described a maximum of $9364.2 \mathrm{~cm}^{2}$ plant $^{-1}$. According to the authors, the rise in the dosage of $\mathrm{N}$ up to a certain limit, provides an increase in the leaf area of the plant.

Cavalcanti et al. (2015) observed that the LA of the 'Mandacarú' melon increased progressively from 29 days after sowing (DAS).
Pereira et al. (2011), also obtained a slow growth of melon LA up to 28 DAT, followed by a rapid increase after this period.

The analysis of the effect of nutrient solution concentrations at each sampling time demonstrates quadratic adjustments for all sampling dates (Figure 7). The maximum leaf area estimates were obtained in a concise range of levels, starting with $60 \%$ at 15 DAT, reaching $1755.36 \mathrm{~cm}^{2}$ plant ${ }^{-1}$, and ending with $61 \%$ at 60 DAT with $4844.08 \mathrm{~cm}^{2}$ plant ${ }^{-1}$.

Our results on LA disagree with those presented by Gratieri et al. (2013). These authors verified an increasing linear growth of the leaf area in the melon variety Bonus $n^{\circ} 2$ in coconut fiber cultivation with the increase of the nitrogen and potassium dose in the nutrient solution, verifying in the concentrations of 280 and $312 \mathrm{mg}$ $\mathrm{L}^{-1}$ of $\mathrm{N}, 9353$ and $7063 \mathrm{~cm}^{2}$ plant ${ }^{-1}$, respectively. The values illustrated in this study were higher than those found in our experience.

Figure 8 displays the adjusted leaf area index (LAI) curves. The maximum LAI was $1.21 \mathrm{~cm}^{2}$ $\mathrm{cm}^{-2}$ obtained at 54 DAT for the concentration

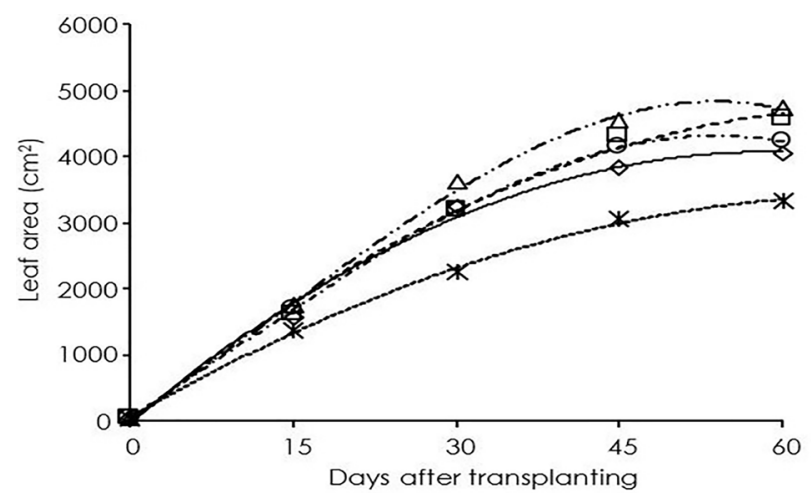

$$
\begin{aligned}
& \diamond 100 \quad \square 75 \quad \Delta 50 \quad 025 \quad * 12.5 \\
& \begin{array}{r}
Y(100)=-1.1782 x^{2 * *}+139.02 x-14.517 \\
R^{2}=0.99^{* *}
\end{array} \\
& Y(100)=-\frac{-0.9748 x^{2 * *}+136.85 x-21.317}{R^{2}=0.99^{* *}} \\
& y(50)=-0.0237 x^{3 *}+0.8714 x^{2}+110.94 x+49.808 \\
& y(25)=-0.0176 x^{3^{*}}+0.4143 x^{2}+107.95 x+66.152 \\
& y(12.5)=-0.6857 x^{2 * *}+96.111 x+69.79
\end{aligned}
$$

Figure 6. Leaf area (LA) of the melon submitted to different concentrations of the nutrient solution throughout the cycle. *Significant at $5 \%(p<0.05)$; **Significant at $1 \%(p<0.01)$.

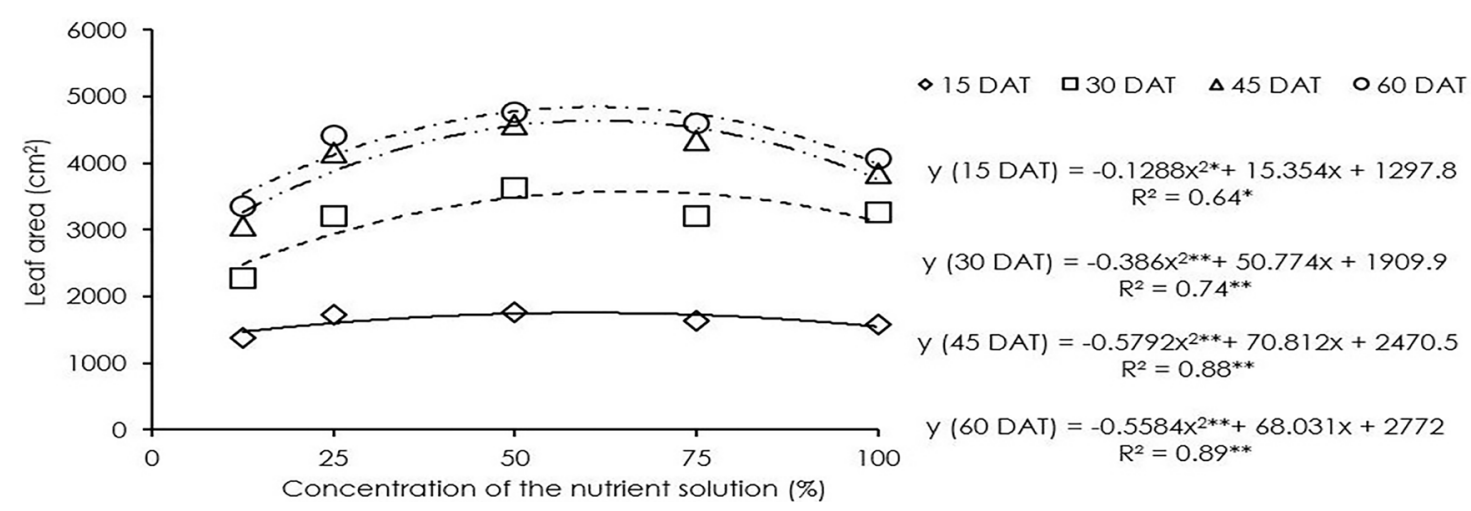

Figure 7. Leaf area (LA) at 15,30, 45 and 60 DAT, depending on the concentration of the nutrient solution. *Significant at 5\% ( $p<0.05$ ); **Significant at $1 \%(\mathrm{p}<0.01)$. 
of $50 \%$ of the nutrient solution $\left(\mathrm{T}_{1}\right)$, followed by treatments $\mathrm{T}_{2}$ and $\mathrm{T}_{4}$, with 1.17 and $1.08 \mathrm{~cm}^{2} \mathrm{~cm}^{-2}$, at 60 and 54 DAT, respectively.

The LAl acts as an indicator of the surface available for interception and light absorption, evaluating the capacity or speed which the aerial parts of the plant (leaf area) occupy the space of soil or another substrate available to that plant (Peixoto \& Peixoto, 2009). Queiroga et al. (2007) using doses of $\mathrm{N}$ in melon obtained a quadratic response on leaf area per plant. Santos et al. (2015), also found a higher value of LAI, observing a maximum value of 1.95 at 55 DAT.

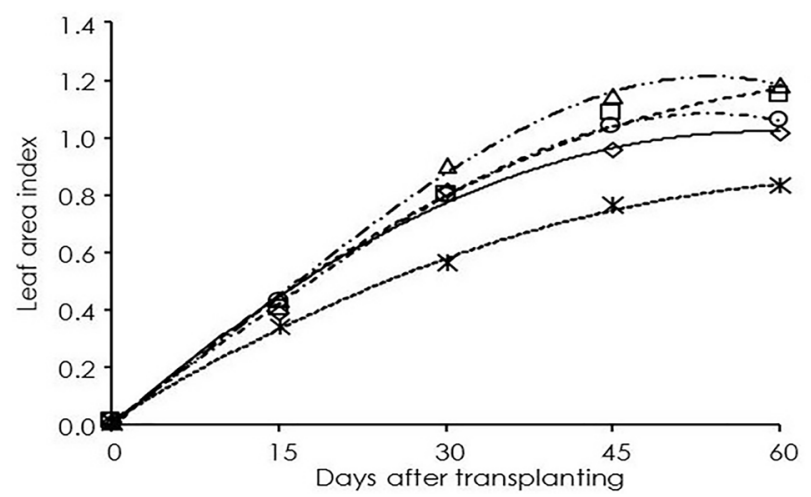

Analyzing the curves for leaf area ratio (LAR) in Figure 10, we can see that maximum values of LAR were obtained in the early vegetative growth of the melon plant, decreasing throughout the cycle. On average, the observed values of LAR were 152.01; 126.28; 108.55 and 92.27 $\mathrm{cm}^{2} \mathrm{~g}^{-1}$, for 15, 30, 45 and 60 DAT, respectively. According to Peixoto \& Peixoto (2009), the LAR declines while the plant grows, due to the selfshading, with a tendency to decrease the useful leaf area or photosynthetically active, for the production of dry matter. This fact is evidenced by the increase of the leaf area index (Figure 8).

Figure 8. Leaf area index (LAI) of the melon submitted to different concentrations of the nutrient solution throughout the cycle. *Significant at $5 \%(p<0.05)$; **Significant at $1 \%(p<0.01)$.
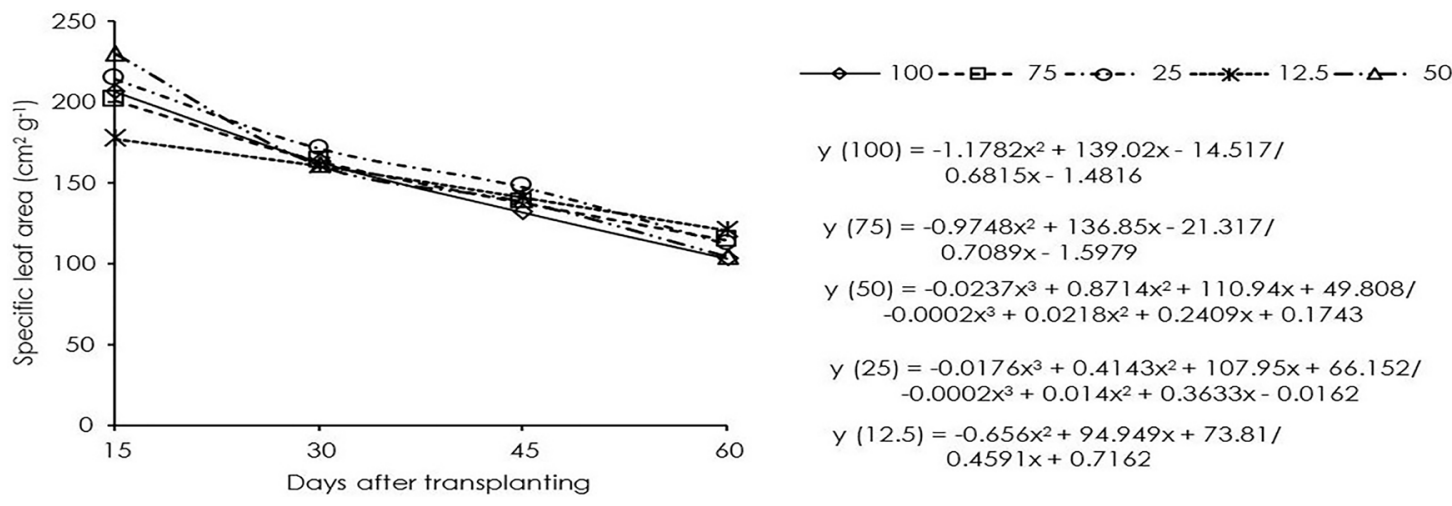

Figure 9. Specific leaf area (SLA) of the melon submitted to different concentrations of the nutrient solution throughout the cycle. ${ }^{*}$ Significant at $5 \%(\mathrm{p}<0.05) ; * *$ Significant at $1 \%(\mathrm{p}<0.01)$.
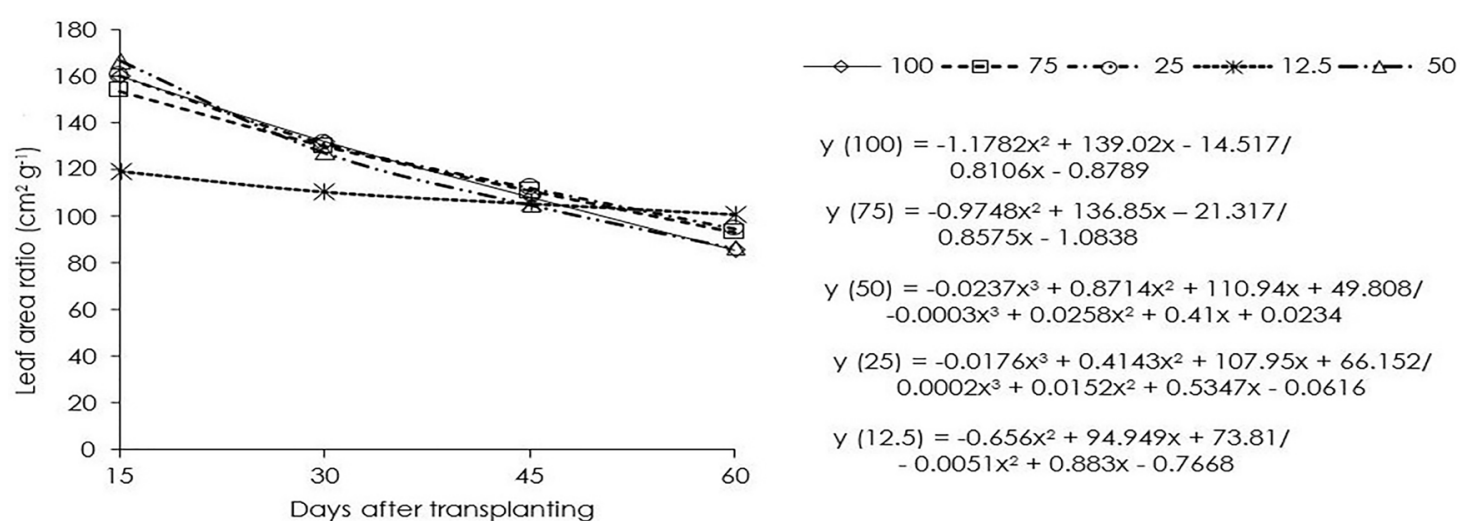

Figure 10. Leaf area ratio (LAR) of melon subjected to different concentrations of the nutrient solution during the cycle. 
According to Cavalcanti et al., 2015, this decrease in LAR throughout the cycle of the melon indicates that some assimilates are gradually destined to the leaves. Andrade (2006) working with Muskmelon (Sancho hybrids) testing Nitrogen and Potassium doses in the melon growth under field conditions obtained results similar to those obtained in this study, where LAR was maximal at the beginning of the vegetative growth phase at 28 DAS. According to this author, from this time a more significant increase occurs the phytomass about the foliar area, that is because in this period there is a smaller development of the branches, stems and flower buds that result in a relatively high amount of phytomass and consequently a decrease of the ratio between both.

Figure 11 presents the absolute growth rate (AAPGR) of the melon and the adjusted curves. The figure highlights that the highest growth occurred for the $T_{3}$ treatment, which corresponds to the $50 \%$ concentration, which reached the maximum growth rate at 29 DAT, reaching $1.17 \mathrm{~g} \mathrm{plant}^{-1}$ day $^{-1}$, followed by $\mathrm{T}_{4}$ treatment (25\% concentration), which reached maximum growth rate at 26 DAT, being observed $0.93 \mathrm{~g} \mathrm{plant}^{-1}$ day $^{-1}$. The treatments $T_{1}$ and $T_{2}$ presented constant absolute growth rates throughout the cycle, with values of 0.81 and 0.86 $g$ plant $^{-1}$ day ${ }^{-1}$, respectively. On the other hand, the $T_{5}$ treatment, with a lower concentration, showed a linearly decreasing growth rate, being at the beginning of the cycle with $0.88 \mathrm{~g} \mathrm{plant}^{-1}$ day $^{-1}$. To evaluate the Nitrogen and Potassium rates in the growth of the melon, Andrade (2006) verified the tendency of the rise in the absolute decrease rate of the aerial part, observing higher values, at 55 and 54 DAS, respectively.

Figure 12 presents the evolution of the relative growth rate of the aerial part (RAPGR) throughout the growing season. A variation of the values along the cycle was observed, where the highest growth was observed in the first weeks. Although the absolute growth rate indicates the speed of growth of the plant, for physiologists it is more interesting to express the relative growth rate, on a common basis, the plant's own weight (Benicasa, 2003).

For the relative growth rate, the $T_{3}$ treatment had the highest RAPGR values of 15 to 30 DAT, being 0.09 and $0.042 \mathrm{~g} \mathrm{~g}^{-1}$ day 1, respectively, and $T_{1}$ and $T_{2}$ treatments at 45 and 60 DAT, where 0.023 and $0.017 \mathrm{~g} \mathrm{~g}^{-1}$ day $^{-1}$, respectively. Similar behavior was obtained by
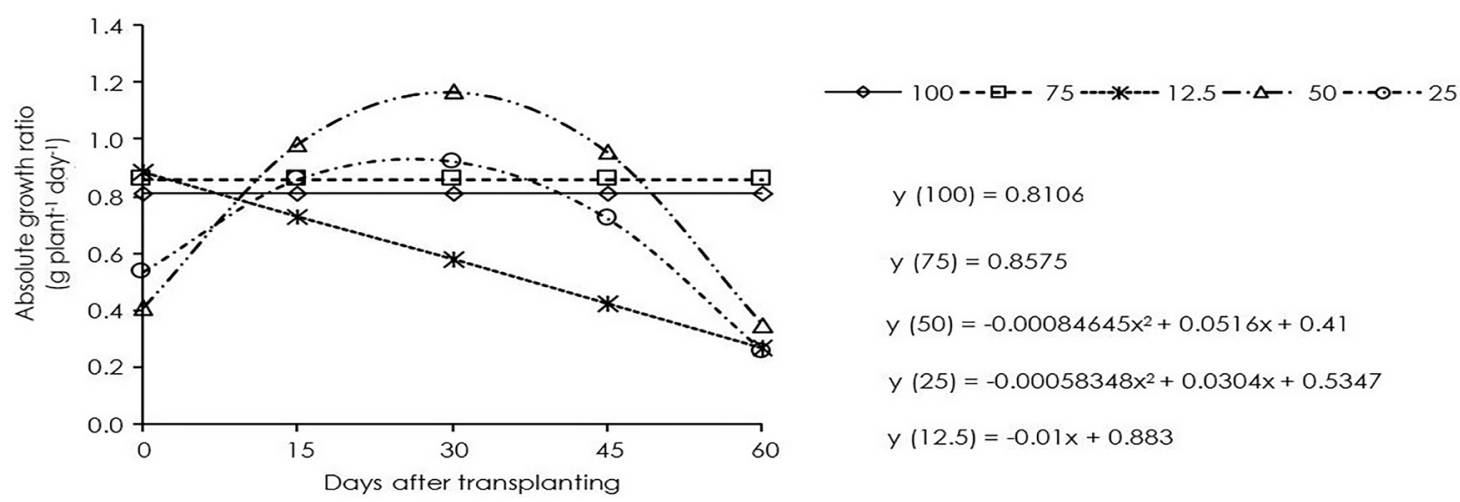

$y(100)=0.8106$

$y(75)=0.8575$

$y(50)=-0.00084645 x^{2}+0.0516 x+0.41$

$y(25)=-0.00058348 x^{2}+0.0304 x+0.5347$

$y(12.5)=-0.01 x+0.883$

Figure 11. Absolute aerial part growth rate (AAPGR) of the melon submitted to different concentrations of the nutrient solution throughout the cycle.
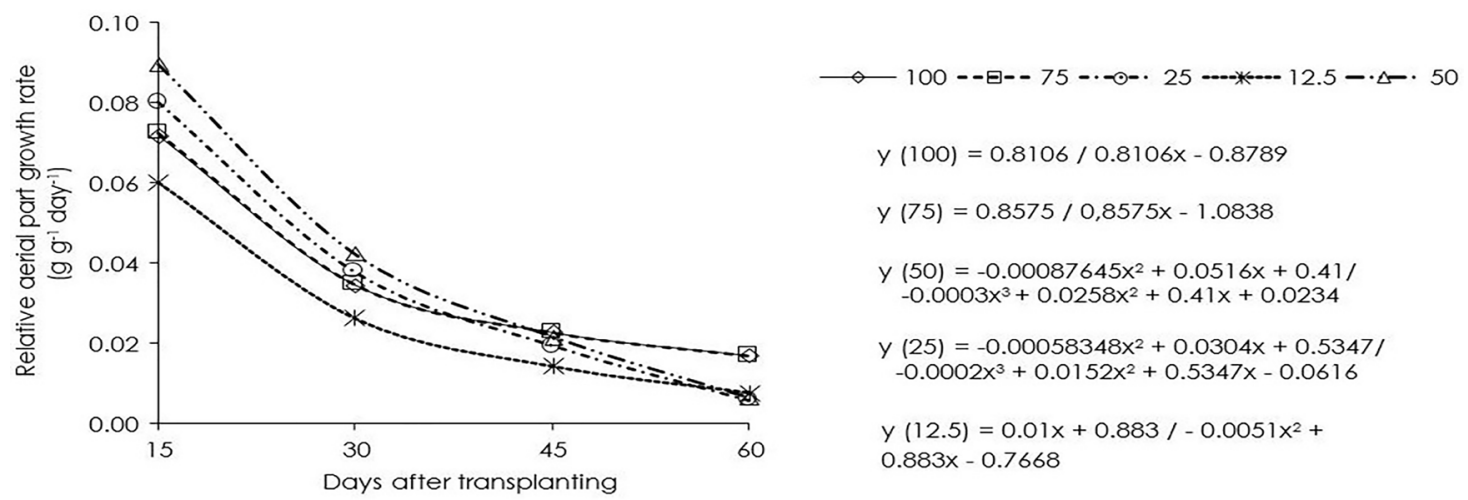

Figure 12. Relative aerial part growth rate (RAPGR) of the melon submitted to different concentrations of the nutrient solution throughout the cycle. 
Andrade (2006), observing high values of RAPGR at the beginning and the end of the cycle of the Muskmelon submitted to different irrigation plates and nitrogen and potassium doses.

Observing the curves generated to describe the net assimilation rate of the aerial part (NARAP), we can see that the treatments provided greater assimilatory gain at the beginning of the cycle, decreasing later with the advance of this one (Figure 13). Up to 45 DAT,

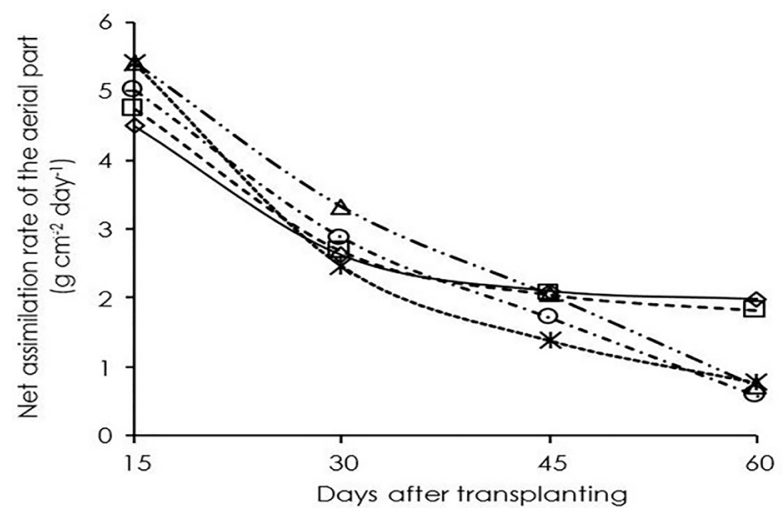

the net assimilation rate was similar between the treatments and from there treatments $T_{1}$ and $T_{2}$ presented a higher net assimilation rate, justifying the higher RAPGR observed for these treatments at 60 DAT (Figure 12). According to Benincasa (2003), RAPGR depends on NARAP and LAR. Thus, the smaller NARAP certainly contributed to the lower RAPGR for the concentrations C3, C4, and $\mathrm{C} 5$.

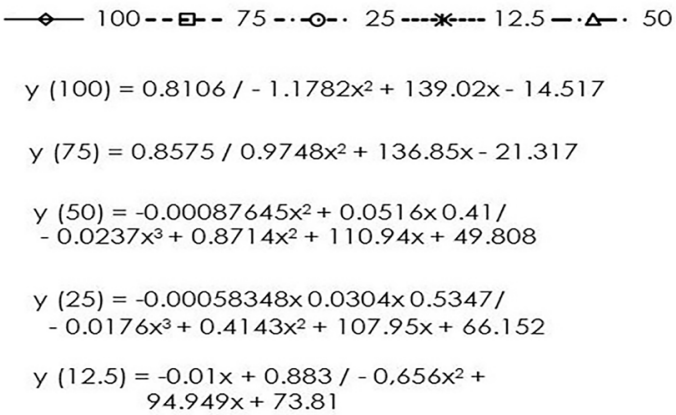

Figure 13. Net assimilation rate of the aerial part (NARAP) of the melon submitted to different concentrations of the nutrient solution throughout the cycle.

\section{Conclusions}

The concentration of $50 \%$ of the standard solution provided higher yields of dry matter and leaf area for 'Galia' type melon.

The concentration of $50 \%$ of the standard solution at 30 DAT provided the highest absolute growth rate.

Regardless of the concentration of the nutrient solution, the relative growth rate of the aerial part and its net assimilation rate displayed the highest values at the beginning of the cycle, decreasing over time.

\section{References}

Andrade, M. E. L. 2006. Growth and productivity of melon under different water depths and nitrogen and potassium rates. $93 \mathrm{p}$ (Masters dissertation). UFERSA. Mossoró, Brazil.

Benincasa, M. M. P. 2003. Analysis of plant growth, basics. FUNEP, Jaboticabal, Brazil. $41 \mathrm{p}$.

Castoldi, R., Charlo, H. C. O., Vargas, P. F., Braz, L. T. 2008. Fruit quality of five hybrids of laced melon according to the number of fruits per plant. Revista Brasileira de Fruticultura 30: 455-458.

Cavalcanti, N. M. S., Dutra, A. F., Melo, A. S., Silva, F. G., Dutra, W. F., Nunes Junior, E. D. S. 2015. Agronomic aspects of 'Mandacarú' melon cultivated in a protected environment under irrigation. Irriga 20: 261-272.
Dias, N. S., Lira, R. B., Brito, R. F., Sousa Neto, O. N., Ferreira Neto, M., Oliveira, A. M. 2010. Production of laced melon in a hydroponic system with desalination waste water in nutrient solution. Revista Brasileira de Engenharia Agrícola e Ambiental 14: 755-761.

Furlani, P. R. 1999. Hydroponic vegetable production in Brazil. Acta Horticulturae 481: $777-$ 778.

Gratieri, L. A., Cecílio Filho, A. B., Barbosa, J. C., Pavani, L. C. 2013. Nitrogen and Potassium Concentrations in the Nutrients Solution for Melon Plants Growing in Coconut Fiber without Drainage. The Scientific World Journal 2013: 1-10.

Kill, L. H. P., Coelho, M. S., Siqueira, K. M. M., Costa, N. D. 2011. Assessment of visitation pattern of Apis mellifera in three types of melon in Petrolina, Pernambuco, Brazil. Revista Brasileira de Fruticultura 33: 455-460.

Mascarenhas, F. R., Medeiros, D. C., Medeiros, J. F., Dias, P. M. S., Morais, M. S. S. 2010. Production and quality of 'Gália' melon grown under different levels of salinity. Revista Verde de Agroecologia e Desenvolvimento Sustentável 5: 171-181.

Peixoto, C. P., Peixoto, M. F. S. P. 2009. Plant growth dynamics: basic principles. In: Carvalho, C. A. L, Dantas, A. C. V. L., Pereira, F. A. C., Soares, A. C. F., Melo Filho, J. F. (Org.). Topics in Agrarian Sciences. Nova Civilização Editorial, Cruz das Almas, Brazil. p. 37-53. 
Pereira, F. H. F., Puiatti, M., Finger, F. L., Cecon, P. R. 2011 . Growth, assimilate partition and yield of melon charenthais under different shading screens. Horticultura Brasileira 29: 91-97.

Queiroga, R. C. F., Puiatti, M., Fontes, P. C. R., Cecon, P. R., Finger, F. L. 2007. Influence of nitrogen rates on yield and quality of Cantalupensis melon under protected environment. Horticultura Brasileira 25: 550-556.

Santos, F. G. B., Negreiros, M. Z., Medeiros, J. F., Nunes, G. H S., Medeiros, D. C., Grangeiro, L. C. 2015. Production and quality of Cantaloupe melon in cultivation temporarily protected with agro-textile in Mossoró, Rio Grande do Norte. Revista Ceres, 62: 93-100.

Silva, W. G., Carvalho, J. D. A., Oliveira, E. C., Rezende, F. C., de Lima Junior, J. A., Rios, G. F. 2012. Irrigation management for the yardlong bean, in the vegetative and productive phases, in a protected environment. Revista Brasileira de Engenharia Agrícola e Ambiental 16: 978-984.

Yamaki, F. L. 2005. Evaluation of different concentrations of nutrient solution in the cultivation of hybrids of laced melon in coconut fiber substrate. $72 \mathrm{p}$ (Masters Dissertation). UNESP. Ilha Solteira, Brazil. 